\title{
Pengembangan Aplikasi Pembelajaran dengan Menerapkan Model Pembelajaran Teams-Games-Tournament (TGT)
}

\section{(Learning Application Development Using a Teams-Games-Tournaments (TGT) Model)}

\author{
Anita Rizky Agustina ${ }^{1}$, Fajar Pradana², Fitra A. Bachtiar ${ }^{3}$
}

\begin{abstract}
UPT SMP Negeri 6 Gresik is one of the few educational institutions that implement a Teams-GamesTournament (TGT) learning model in their day-to-day class learning activities. The TGT learning model can assist students in understanding the learning materials by relying on their friends as age-equivalent tutors and via game elements. The current model that was being applied has several issues, where teachers formed the groups conventionally which could decrease the inclass study time. Conventional ways of forming a group leave room for an unfair knowledge distribution among groups, such as a group having only students who have high grades or low grades only. Other than that, the teachers will make a crossword puzzle conventionally. The playing board is made before a learning material is given to the students and the amount of "words" on the puzzle are determined on much material there is and how many groups are formed. The grouping feature is developed using $\mathbf{k}$ means clustering. The development process used the waterfall development process and Codeigniter framework. This application requirement analysis resulted in four actors, 37 functional requirements, and one non-functional requirement. Testing for this research was done by blackbox testing techniques and whitebox testing techniques.
\end{abstract}

Intisari-UPT SMP Negeri 6 Gresik adalah salah satu lembaga pendidikan yang menerapkan model pembelajaran TeamsGames-Tournament (TGT) dalam kegiatan belajar-mengajar di kelas. Model pembelajaran TGT dapat membantu siswa dalam memahami materi pelajaran dengan mengandalkan teman sebagai tutor sebaya dan memanfaatkan unsur permainan di dalamnya. Model pembelajaran yang diterapkan saat ini memiliki beberapa kendala, di antaranya guru membentuk kelompok secara konvensional, yang dapat mengurangi jam belajarmengajar di kelas. Pembentukan kelompok secara konvensional memungkinkan pembagian kelompok yang tidak merata, yaitu terdapat kelompok yang terdiri atas siswa yang memiliki nilai unggul saja atau rendah saja. Selain itu, guru membuat papan permainan berupa Teka-Teki Silang (TTS) secara konvensional. Papan permainan dibuat sebelum penyampaian materi diberikan dan dibuat juga sejumlah materi dan kelompok yang ada. Fitur pengelompokan dikembangkan dengan menerapkan algoritme $k$ means clustering. Proses pengembangan sistem ini menerapkan model pengembangan waterfall dan framework CodeIgniter. Analisis kebutuhan yang dilakukan untuk aplikasi in menghasilkan empat aktor, 37 kebutuhan fungsional, dan satu

1,2,3 Universitas Brawijaya, Jalan Veteran, Malang, Indonesia, 65145 (tlp: 0341-551611 ext: 126; fax: 0341-565420; e-mail: anitarizkyagustina@gmail.com; fitra.bachtiar@ub.ac.id) kebutuhan nonfungsional. Pengujian dilakukan dengan menggunakan teknik blackbox testing dan whitebox testing.

Kata Kunci-Model Pembelajaran, Teams-Games-Tournament, $K$ Means, Clustering, Waterfall.

\section{Pendahuluan}

Sekolah adalah suatu lembaga pendidikan yang diperuntukkan sebagai tempat kegiatan belajar mengajar [1] Sekolah merupakan sarana untuk mengembangkan potensi pada anak-anak dan remaja. UPT SMP Negeri 6 Gresik merupakan salah satu sekolah atau lembaga pendidikan yang banyak menorehkan prestasi dalam bidang akademik maupun nonakademik. Pada kegiatan belajar mengajar di kelas, pengajar atau guru di UPT SMP Negeri 6 Gresik menggunakan model pembelajaran Teams-Games-Tournament (TGT).

Model pembelajaran TGT termasuk dalam tipe pembelajaran kooperatif, yang mengelompokkan peserta didik beranggotakan tiga hingga lima orang. Dalam satu kelompok tersebut terdapat peserta didik dengan kemampuan, suku atau ras, dan jenis kelamin yang berbeda [2]. Model pembelajaran TGT dapat membantu siswa dalam memahami materi yang disampaikan guru karena pada model pembelajaran TGT terdapat unsur permainan yang dapat memudahkan peserta didik dalam memahami materi yang disampaikan oleh guru dan mengandalkan teman sebaya sebagai tutor [3]. Referensi [4] menyatakan bahwa terdapat lima komponen dalam model pembelajaran TGT, yaitu presentasi kelas, kelompok atau tim, game, turnamen, dan team recognize atau penghargaan kelompok. Implementasi penggunaan model pembelajaraan TGT ini bertujuan agar siswa memiliki pengetahuan mata pelajaran yang sama rata dengan acuan nilai ujian yang tidak jauh berbeda dan lebih memacu minat dan motivasi siswa dalam memahami pelajaran dengan adanya unsur permainan di dalamnya.

Pada penelitian sebelumnya, guna mengetahui adanya peningkatan aktivitas dan prestasi belajar pada salah satu mata pelajaran, yaitu mata pelajaran Ilmu Pengetahuan Alam (IPA), dengan menggunakan model pembelajaran TGT, digunakan subjek penelitian siswa kelas IV SD Negeri Guwo Tahun Ajaran 2015/2016. Sebelum dilakukan tindakan, hasil prestasi belajar siswa memiliki rata-rata sebesar $22,22 \%$, dengan kriteria "Kurang". Setelah dilakukan tindakan, diperoleh ratarata persentase siswa yang mencapai ketuntasan sebesar $66,67 \%$, dengan kriteria "Baik" dan pada siklus II diperoleh rata-rata persentase sebesar $88,89 \%$, dengan kriteria "Baik Sekali" [5]. Pada penelitian lainnya, digunakan server-script 
PHP dan basis data MySQL untuk menyederhanakan penerapan model pembelajaran TGT. Penyederhanaan yang dilakukan adalah dengan mengelompokkan siswa dalam mode virtual dan aplikasi akan menghitung secara otomatis poin turnamen [6]. Pada penelitian lainnya, yang pernah dilakukan adalah dengan menerapkan model pembelajaran TGT menggunakan Flash ChemQuiz untuk meningkatkan minat dan prestasi belajar materi hidrokarbon. Penelitian yang dilakukan adalah penelitian tindakan kelas yang dilakukan dalam dua siklus dan pada penelitian ini digunakan salah satu media, yaitu Flash ChemQuiz, yang harus diselesaikan siswa pada saat belajar berkelompok dan pertandingan. Pada penelitian ini, dihasilkan kesimpulan yaitu terjadi peningkatan prestasi belajar pada aspek kognitif pada siklus I sebesar 43,33\% dan pada siklus II meningkat menjadi $83,33 \%$. Prestasi belajar pada aspek afektif pada siklus I sebesar 93,33\% [7].

Model pembelajaran TGT yang saat ini sedang diterapkan di UPT SMP Negeri 6 Gresik memiliki beberapa kendala. Kendala yang ditemui adalah guru membentuk kelompok secara konvensional, yaitu dengan cara berhitung atau secara acak. Pembentukan kelompok yang dilakukan saat ini memungkinkan pembagian kelompok yang tidak merata, yaitu terdapat kelompok yang terdiri atas siswa yang memiliki nilai lebih unggul atau rendah saja (homogen). Pembentukan kelompok yang diterapkan saat ini juga membutuhkan waktu yang dapat mengurangi jam belajar-mengajar di kelas.

Kendala lain yang ditemui adalah guru membuat papan permainan berupa Teka-Teki Silang (TTS) secara konvensional. Guru membuat papan permainan sejumlah kelompok yang ada di kelas dan sejumlah materi yang ada. Kegiatan tersebut dinilai kurang efisien karena papan permainan perlu dibuat dan disesuaikan dengan materi pelajaran yang ada dan dicetak sejumlah kelompok yang ada di kelas.

Kendala yang dialami, selain pembentukan kelompok dan pembuatan papan permainan secara konvensional, adalah dalam hal penghitungan nilai siswa dalam menjawab pertanyaan TTS dan penghitungan total nilai dalam kelompok belajar. Penghitungan yang diterapkan di kelas saat ini adalah dengan cara siswa menghitung sendiri jawaban benar, kemudian siswa menulis nilai yang didapatkan di kertas. Kertas tersebut kemudian dikumpulkan ke perwakilan kelompok lalu diserahkan ke guru. Kertas yang telah terkumpul akan dihitung jumlahnya oleh guru, kemudian guru akan menentukan kelompok belajar yang akan mendapat predikat super team, great team, dan good team.

Berdasarkan permasalahan yang telah diuraikan, diperlukan sistem yang dapat digunakan untuk mempermudah pengelompokan dan pembuatan papan permainan oleh guru. Pengelompokan dilakukan berdasarkan nilai siswa dan aspek lain, yaitu jenis kelamin, dengan menggunakan algoritme $K$ Means clustering. Penggunaan algoritme $K$-Means clustering dikarenakan algoritme $K$-Means merupakan salah satu metode pengelompokan yang mengelompokkan data dengan kondisi data dalam satu kelompok mempunyai kesamaan pada karakteristik datanya [8], sehingga dapat terbentuk kelompok yang setara antara satu dengan lainnya. Aplikasi pembelajaran

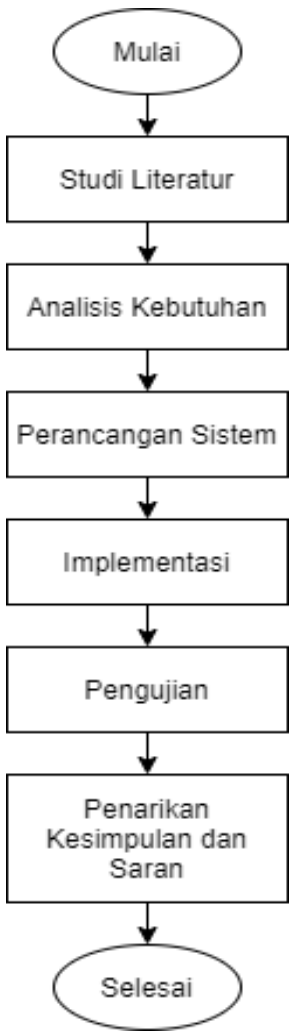

Gbr. 1 Diagram alir metodologi penelitian.

yang dirancang dan dibangun memiliki batasan, yaitu sebagai pendukung dalam persiapan kegiatan belajar mengajar dengan menggunakan model pembelajaran TGT. Dalam pengembangan sistem, digunakan model pengembangan perangkat lunak waterfall dan framework CodeIgniter. Pengujian perangkat lunak menggunakan teknik pengujian blackbox dan pengujian whitebox.

\section{Metodologi}

Penjabaran langkah-langkah perancangan penelitian yang dilakukan merupakan pengertian dari metodologi penelitian. Alur atau langkah-langkah yang dilakukan guna menyelesaikan penelitian ini diperlihatkan pada Gbr. 1.

Tahap studi literatur dilakukan dengan mengumpulkan studi kepustakaan yang dapat menunjang penulisan penelitian yang dilakukan. Selain studi literatur, studi lapangan juga dilakukan guna mengetahui proses di lapangan. Teknik pengumpulan data yang dilakukan adalah observasi dan wawancara. Teknik wawancara dilakukan dengan mengumpulkan permasalahan yang didapatkan oleh pelaku yang terlibat dalam proses belajar mengajar. Hasil dari wawancara diolah menjadi kebutuhankebutuhan sebagai dasar atau acuan dalam membangun sistem yang sesuai dengan kebutuhan pengguna.

Kebutuhan yang harus ada dalam sistem dilakukan pada tahap analisis kebutuhan. Dalam tahap analisis kebutuhan, dilakukan penggambaran secara umum perangkat lunak yang dikembangkan, identifikasi aktor yang terlibat dalam sistem, identifikasi diagram use case, dan skenario use case [9].

Tahap perancangan sistem merupakan dasar dalam melakukan implementasi dalam pengembangan sebuah 


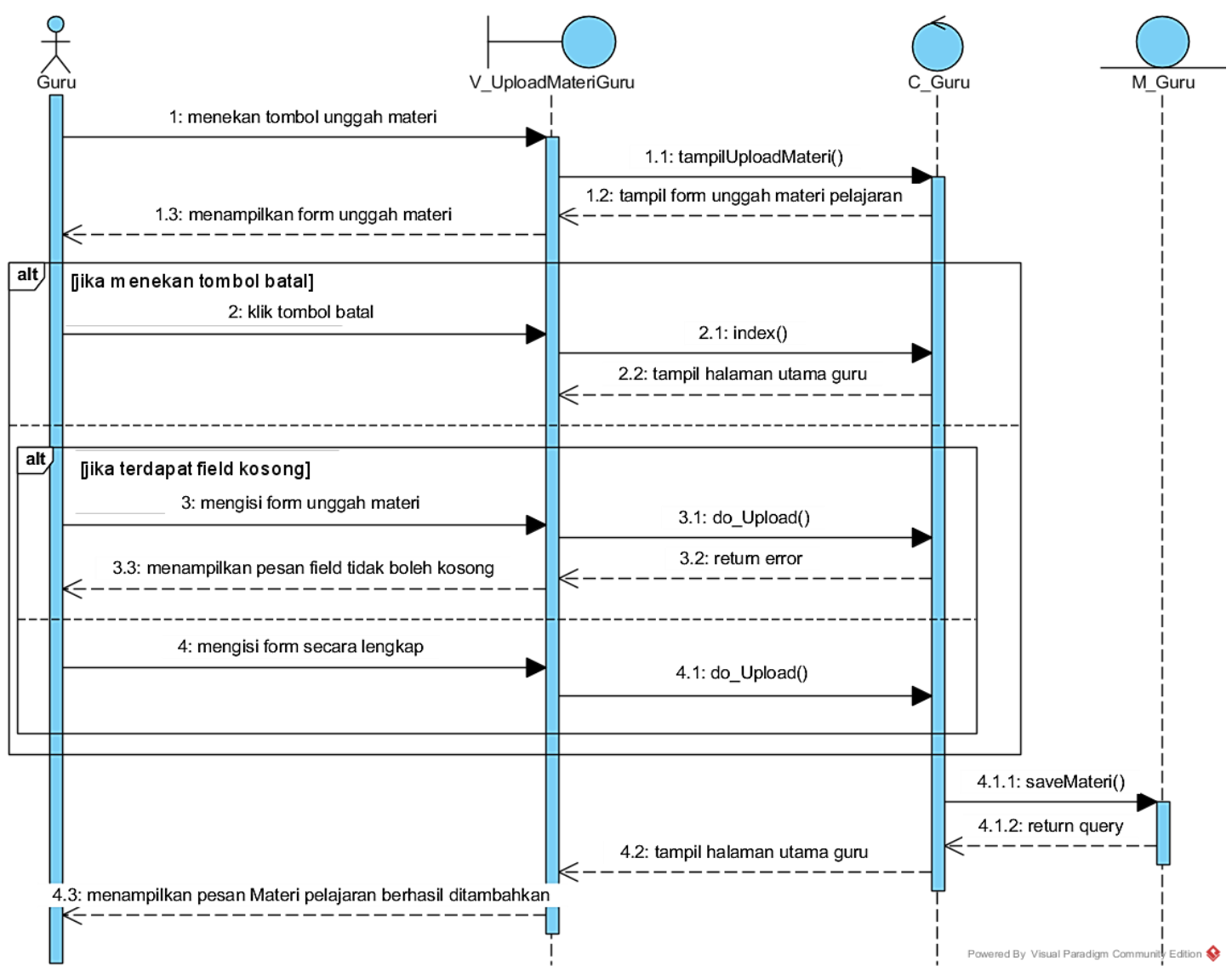

Gbr. 2 Sampel perancangan diagram sequence do_Upload.

perangkat lunak. Setelah melakukan tahap analisis kebutuhan, selanjutnya dilakukan pemodelan kebutuhan dalam bentuk Unified Modeling Language (UML) [10]. Terdapat beberapa hal yang dilakukan dalam pemodelan UML, yaitu perancangan diagram class, diagram sequence, database atau basis data, dan antarmuka. Desain yang selesai dirancang selanjutnya diubah ke dalam kode-kode program.

Pencarian kesalahan dalam perangkat lunak dilakukan pada tahap pengujian. Tahap pengujian dilakukan agar perangkat lunak yang diserahkan ke pengguna tidak mengalami kesalahan maupun kendala dan terkirim dalam kondisi sesuai dengan kebutuhan pengguna. Teknik pengujian yang digunakan yaitu teknik pengujian kotak hitam atau blackbox dan teknik pengujian kotak putih atau whitebox. Perbaikan dilakukan berdasarkan kesalahan-kesalahan yang ditemui ketika dilakukan pengujian [11].

Tahap terakhir dalam pengembangan sistem adalah melakukan penarikan kesimpulan dan saran. Penarikan kesimpulan dilakukan berdasarkan hasil yang didapatkan dalam tahap-tahap yang telah dilaksanakan. Pemberian saran ditujukan sebagai masukan untuk pengembangan perangkat lunak selanjutnya.

\section{HASIL DAN PEMBAHASAN}

\section{A. Analisis Kebutuhan}

Analisis kebutuhan merupakan suatu langkah awal dalam pengembangan sistem. Analisis kebutuhan dilakukan guna memastikan kebutuhan yang perlu ada dalam aplikasi. Kebutuhan diperoleh dari hasil studi lapangan di UPT SMP Negeri 6 Gresik dengan teknik wawancara. Fase analisis kebutuhan memperoleh empat aktor yang berkaitan dengan sistem dan 37 kebutuhan fungsional. Empat sampel kebutuhan fungsional dipaparkan pada Tabel I, sedangkan kebutuhan nonfungsional dipaparkan dalam Tabel II.

\section{B. Perancangan dan Implementasi}

Tahap perancangan dilakukan dengan lima tahap, yaitu perancangan diagram sequence, diagram class, basis data, algoritme, dan antarmuka. Setelah tahap perancangan sistem, selanjutnya adalah tahap implementasi. Dalam tahap implementasi dilakukan perubahan perancangan sistem ke dalam bentuk kode program menjadi satu sistem perangkat lunak.

1) Perancangan Diagram Sequence: Diagram sequence mereprentasikan alur jalannya sebuah interaksi antar objek yang terjadi pada sistem. Objek didapatkan dari analisis kebutuhan dan skenario use case. Sampel perancangan diagram sequence ditunjukkan pada Gbr. 2.

2) Perancangan Diagram Class: Identifikasi kelas, objek, dan interaksi dalam sistem dilakukan pada tahap perancangan digram class. Kelas-kelas diperoleh dengan memeriksa objek yang ada pada diagram sequence. Diagram class dari aplikasi pembelajaran berbasis TGT atas dari empat kelas controller, tiga kelas model, dan 37 kelas view. 


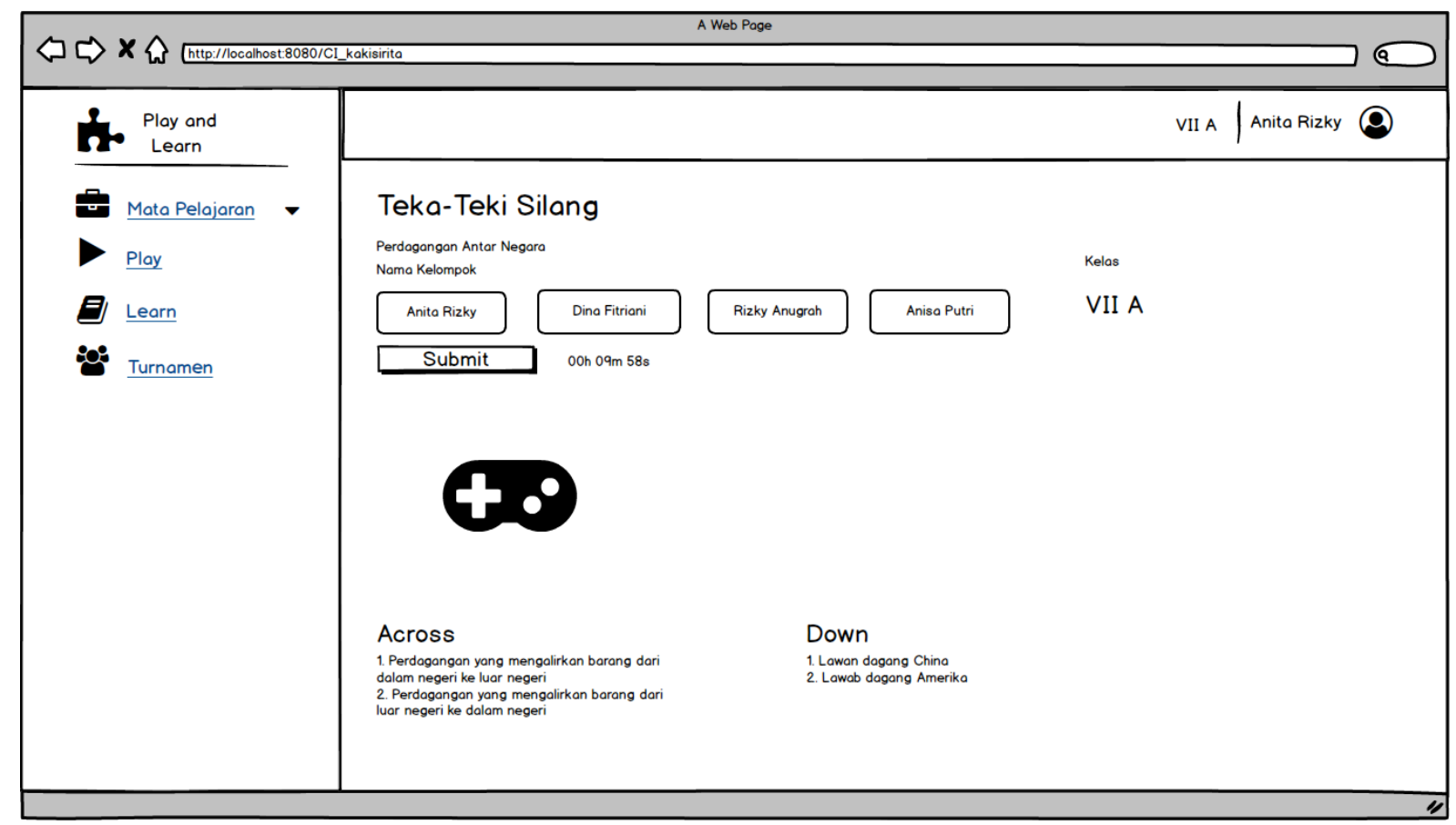

Gbr. 3 Sampel perancangan antarmuka.

TABEL I

SAMPEL KeBUtUHAN FUnGSIONAL

\begin{tabular}{|c|c|c|}
\hline Nama Fungsi & $\begin{array}{c}\text { Kode } \\
\text { Kebutuhan }\end{array}$ & Deskripsi Kebutuhan \\
\hline $\begin{array}{c}\text { Mengunduh Materi } \\
\text { Pelajaran }\end{array}$ & APT_F_004_00 & $\begin{array}{c}\text { Sistem dapat mengunduh } \\
\text { materi pelajaran. }\end{array}$ \\
\hline $\begin{array}{c}\text { Membentuk } \\
\text { Kelompok Belajar } \\
\text { Siswa }\end{array}$ & APT_F_018_00 & $\begin{array}{c}\text { Sistem dapat membentuk } \\
\text { kelompok belajar siswa. }\end{array}$ \\
\hline $\begin{array}{c}\text { Membuat Papan } \\
\text { Permainan Teka- } \\
\text { Teki Silang }\end{array}$ & APT_F_017_00 & $\begin{array}{c}\text { Sistem dapat membuat } \\
\text { papan permainan teka- } \\
\text { teki silang. }\end{array}$ \\
\hline $\begin{array}{c}\text { Menambah Data } \\
\text { Guru }\end{array}$ & APT_F_028_00 & $\begin{array}{c}\text { Sistem dapat } \\
\text { menambahkan data guru. }\end{array}$ \\
\hline
\end{tabular}

TABEL II

KEBUtUHAN NONFUNGSIONAL

\begin{tabular}{|c|l|c|}
\hline Parameter & Kode Kebutuhan & Deskripsi Kebutuhan \\
\hline Kompatibilitas & APT_NF_001_00 & $\begin{array}{c}\text { Sistem yang dibangun } \\
\text { dapat berjalan di } \\
\text { berbagai peramban. }\end{array}$ \\
\hline
\end{tabular}

3) Perancangan Basis Data: Perancangan basis data dibuat dengan menentukan data yang dibutuhkan untuk disimpan terkait dengan aplikasi pembelajaran yang akan dikembangkan. Perancangan basis data dibuat secara konseptual menggunakan Entity Relationship Diagram (ERD). Terdapat sebelas entitas yang dibutuhkan, yaitu user atau siswa, guru, admin, mata pelajaran, materi pelajaran, kelas, bank soal, hasil TTS siswa, data nilai, papan TTS, dan kelompok belajar.

4) Perancangan Algoritme: Penggambaran proses algoritme dari sebuah proses pada sebuah sistem dijelaskan dalam perancangan algoritme. Algoritme fungsi direprentasikan dalam bentuk pseudocode. Beberapa contoh algoritme fungsi yang ada pada aplikasi pembelajaran ini adala algoritme fungsi buatKelompok pada kelas C_Guru, tampilMateriSiswa pada kelas C_Siswa, dan do_upload pada kelas C_Guru.

5) Perancangan Antarmuka: Perancangan antarmuka menjelaskan antarmuka aplikasi pembelajaran berbasis TGT yang akan dikembangkan. Salah satu model antarmuka yang digunakan sebagai sampel dalam perancangan antarmuka adalah perancangan antarmuka halaman tambah data guru. Sampel perancangan antar muka diperlihatkan pada Gbr. 3.

6) Implementasi Basis Data: Implementasi basis data menghasilkan tabel-tabel yang berelasi yang ditujukan untuk menjalankan fungsionalitas sistem. Tabel-tabel tersebut dibentuk berdasarkan perancangan basis data yang telah dirancang. PHPMyAdmin digunakan dalam tahap implementasi basis data. Dari hasil implementasi basis data diperoleh sebelas tabel, yaitu user, guru, admin, mata pelajaran, materi pelajaran, kelas, bank soal, hasil TTS siswa, data nilai, papan TTS, dan kelompok belajar. Penggambaran physical data model ditunjukkan pada Gbr. 4.

7) Implementasi Kode Program: Kode program yang telah dirancang selanjutnya diubah ke dalam kode-kode program pada tahap implementasi. Bahasa pemrograman yang diterapkan dalam tahap implementasi adalah bahasa pemrograman PHP dan HTML.

Tahap kode program diawali dengan memeriksa autentikasi jenis user, kemudian membuat form validasi pada variabel nama_materi, idmatpel, dan kelas. Selanjutnya, dilakukan inisialisasi variabel nama_materi tersebut dengan mengambil 


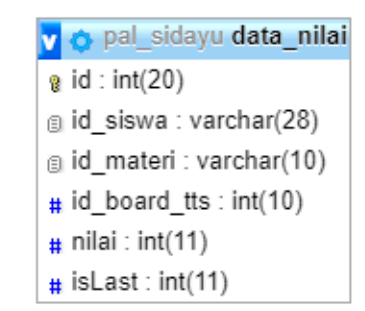

\begin{tabular}{|c|}
\hline pal_sidayu guru \\
\hline id_guru : varchar(20) \\
\hline (1) nama_guru : varchar(128) \\
\hline (1) password_guru : varchar(258) \\
\hline 目 id_matpel : varchar(8) \\
\hline (⿴囗⿱一一) id_kelas : varchar(15) \\
\hline
\end{tabular}

\begin{tabular}{|c|}
\hline pal_sidayu user \\
\hline id_siswa : varchar(15) \\
\hline 自 nama_siswa : varchar(128) \\
\hline (1) password_siswa : varchar(258) \\
\hline \# jenis_kelamin : int(1) \\
\hline \# nilai_siswa1: int(3) \\
\hline (id_kelas : varchar(3) \\
\hline
\end{tabular}

\begin{tabular}{|c|c|}
\hline $\mathbf{v}$ op pal_sidayu kelompok_belajar & $\mathbf{v}$ opal_sidayu hasil_tts_siswa \\
\hline id_kelompok: int(11) & id : int(11) \\
\hline \# id_board_tts : int(11) & (⿴囗⿱一一) id_siswa : varchar(20) \\
\hline 目 id_siswa : text & \# id_board_tts : int(11) \\
\hline (⿴) nilai : varchar(155) & \# id_pertanyaan : int(11) \\
\hline & \# id_nilai : int(11) \\
\hline & lawaban : varchar(250) \\
\hline & $\#$ hasil : tinyint(1) \\
\hline
\end{tabular}

vo pal_sidayu mata_pelajaran

C. id_matpel : varchar(15)

目 nama_matpel : text

\section{vo pal_sidayu materi_pelajaran}

(2) id_materi : int(125)

(1) id_matpel : varchar(8)

Gid_kelas : $\operatorname{varchar}(10)$

目 nama_materi : varchar(255)

(⿴) file_materi : varchar(255)

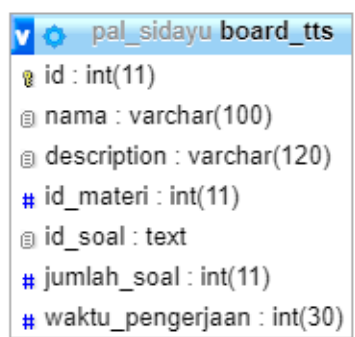

o pal sidayu admin

1] id_admin : int(20)

(1) nama_admin : varchar(20)

(⿴) password_admin : varchar(258)

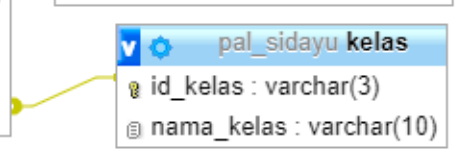

Gbr. 4 Implementasi basis data.

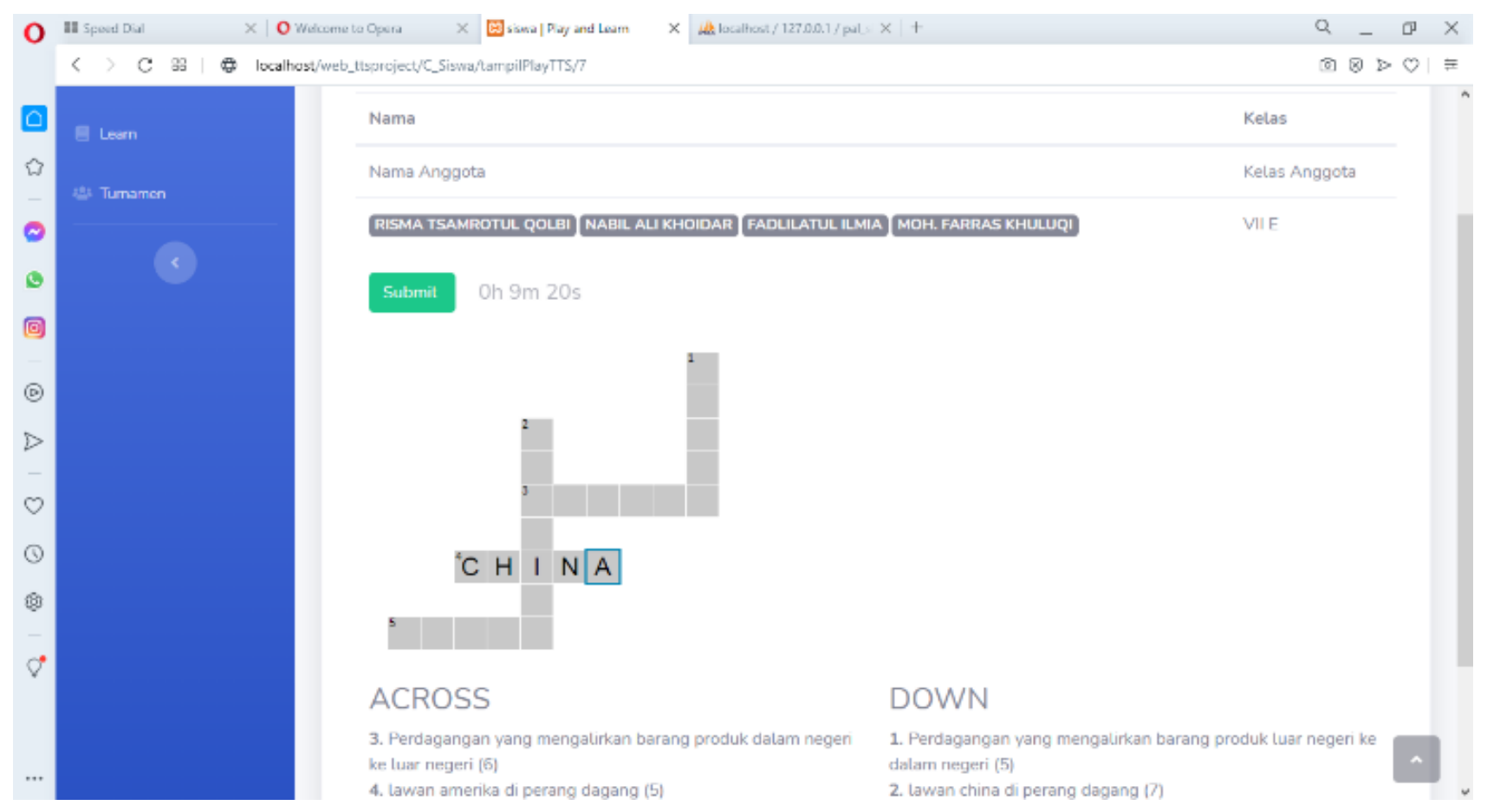

Gbr. 5 Sampel implementasi antarmuka.

post input nama_materi. Tahap selanjutnya adalah inisialisasi variabel cek_materi dengan nilai hasil proses pemilihan data dalam tabel materi pelajaran dengan kondisi atribut nama_materi sama dengan variable nama_materi. Jika form validasi bernilai salah, program akan memanggil method tampilUploadMateri. Kemudian, jika nilai pada variabel cek_materi bernilai benar, program akan memanggil fungsi set_flashdata dari class session dan memanggil fungsi
tampilUploadMateri. Jika form validasi bernilai benar, program akan memanggil fungsi saveMateri pada class model M_Guru dan kemudian mengarahkan ke fungsi tampilDaftarMateri.

8) Implementasi Antarmuka: Implementasi antarmuka merupakan media interaksi antara aktor dengan sistem. Implementasi dilakukan dengan mengacu pada perancangan antarmuka yang telah dilakukan. Sampel implementasi antarmuka ditunjukkan pada Gbr. 5. 


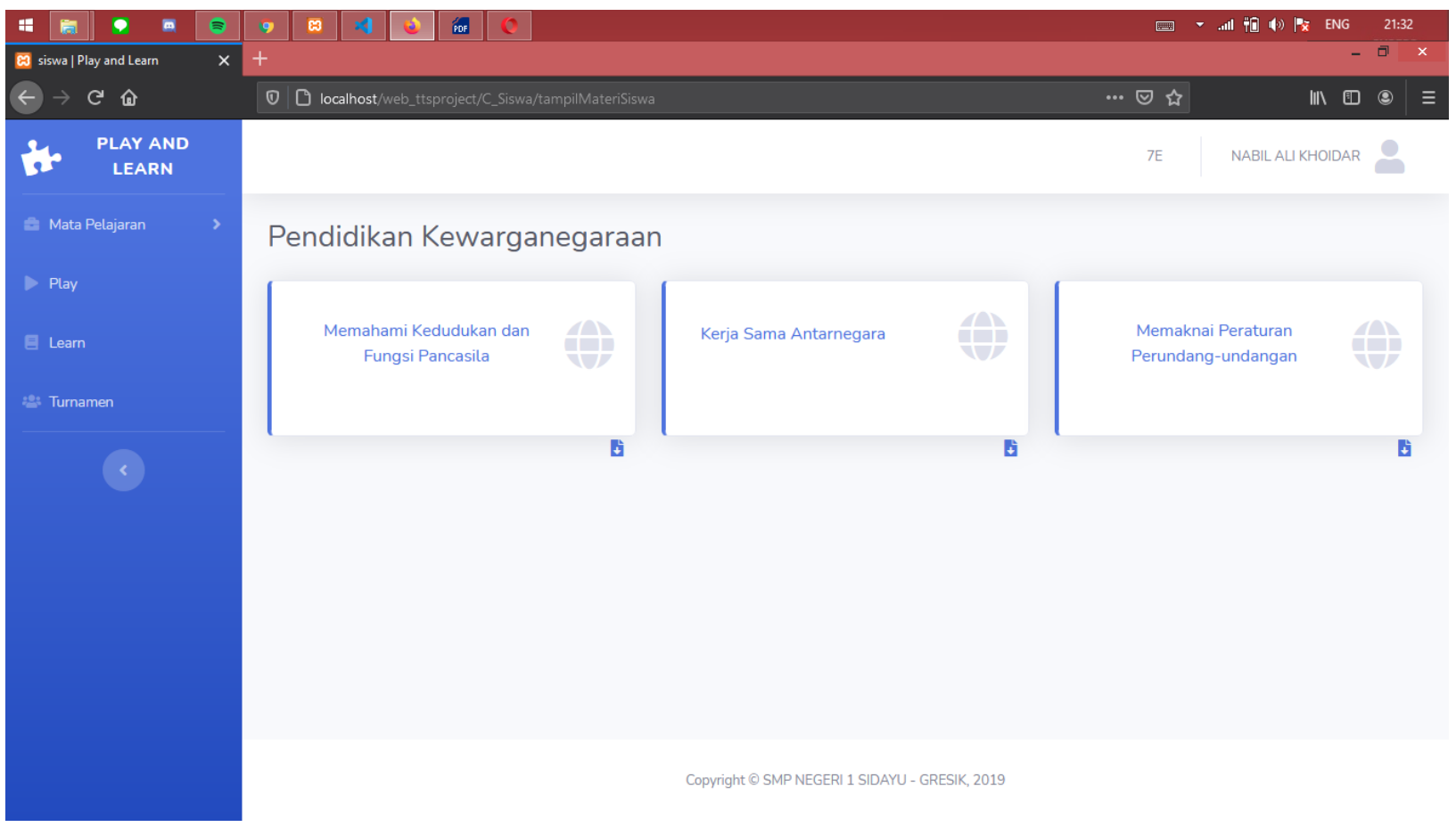

Gbr. 6 Sampel pengujian kompatibilitas pada peramban Mozilla Firefox.

TABEL III

SAmpel Pengujian Validasi

\begin{tabular}{|l|l|}
\hline Nama kasus uji & Menambah data guru \\
\hline pengujian & $\begin{array}{l}\text { 1. Aktor telah login sebagai admin dan } \\
\text { masuk ke halaman utama admin. }\end{array}$ \\
& $\begin{array}{l}\text { 2. Aktor menekan tombol "Tambah } \\
\text { Guru". }\end{array}$ \\
& $\begin{array}{l}\text { 3. Sistem menampilkan halaman } \\
\text { berisikan form data guru. }\end{array}$ \\
& $\begin{array}{l}\text { 4. Aktor mengisi kolom data guru } \\
\text { berupa nomor induk pegawai, nama } \\
\text { lengkap, password guru, mata } \\
\text { pelajaran yang diampu, dan kelas } \\
\text { yang diampu. }\end{array}$ \\
\hline $\begin{array}{l}\text { Hasil yang } \\
\text { diharapkan }\end{array}$ & $\begin{array}{l}\text { Dator menekan tombol "Simpan Data } \\
\text { dan suruan tersimpan ke basis data } \\
\text { nama guru. }\end{array}$ \\
\hline Hasil & $\begin{array}{l}\text { Sistem menyimpan data guru ke basis data } \\
\text { dan menampilkan halaman daftar nama } \\
\text { guru. }\end{array}$ \\
\hline Status & Valid. \\
\hline
\end{tabular}

\section{Pengujian}

1) Pengujian Unit: Pengujian unit adalah salah satu strategi pengujian perangkat lunak. Setiap unit atau bagian dari perangkat lunak yang telah diimplementasikan diuji guna memastikan sistem berjalan dengan baik. Pada pengujian unit, diterapkan teknik pengujian basis path, yaitu jalur yang dibuat dapat diujikan dan dapat berjalan sesuai dengan alurnya.

2) Pengujian Integrasi: Pengujian integrasi ialah pengujian yang dilakukan dengan uji interaksi antar kelas. Teknik pengujian basis path diterapkan dalam pengujian integrasi dengan pendekatan top-down. Pengujian top-down diawali dari modul yang lebih besar kemudian dekomposisi ke modul yang lebih kecil.

3) Pengujian Validasi: Pengujian validasi ditunjukkan guna mengetahui kesesuaian aplikasi dengan kebutuhan dan merupakan hasil analisis kebutuhan. Pada pengujian validasi, digunakan teknik pengujian blackbox. Sampel pengujian validasi dijabarkan pada Tabel III.

Pengujian kompatibilitas atau compatibility termasuk dalam pengujian kotak hitam atau blackbox. Pengujian dikerjakan dengan menjalankan semua fungsi sistem sesuai dengan skenario pada pengujian validasi melalui beberapa macam peramban guna memperlihatkan sistem dapat digunakan dengan baik di setiap peramban atau tidak. Hasil pengujian kompatibilitas dengan menggunakan aplikasi Sortsite adalah sistem dapat berjalan pada peramban Chrome, Internet Explorer, Opera, Internet Edge, Mozilla Firefox, Safari, iOS 12 13, dan 14, serta Android. Sampel pengujian kompatibilitas pada peramban Mozilla Firefox diperlihatkan pada Gbr. 6.

\section{KESIMPULAN DAN SARAN}

Berdasarkan perancangan dan pengembangan aplikasi pembelajaran TGT yang telah dilakukan, dapat ditarik kesimpulan bahwa pada fase analisis kebutuhan didapatkan empat aktor yang terlibat dalam aplikasi, 37 kebutuhan fungsional, dan satu kebutuhan nonfungsional. Perancangan aplikasi dapat disusun dalam bentuk perancangan diagram sequence, diagram class, basis data, algoritme, dan perancangan antarmuka. Pada fase implementasi diperoleh sistem aplikasi pembelajaran yang memiliki fitur-fitur penting, yaitu membentuk kelompok belajar siswa, menambahkan 
materi pelajaran, mengunduh materi pelajaran, menambahkan soal permainan, dan membuat papan permainan teka-teki silang. Bahasa yang digunakan dalam pengembangan sistem adalah bahasa pemrograman PHP dan HTML. Basis data MySQL dan framework CodeIgniter juga digunakan dalam pengembangan sistem. Pengujian validasi dilakukan terhadap 59 kasus uji pada 37 kebutuhan fungsional dengan hasil 100\% valid. Uji validasi parameter kompatibilitas pada pengujian nonfungsional dilakukan dengan menggunakan aplikasi Sortsite yang menunjukkan bahwa aplikasi dapat berjalan pada delapan macam peramban.

Untuk pengembangan selanjutnya, dapat dilakukan penambahan fitur pemberitahuan pada halaman siswa guna mengetahui adanya permainan atau materi baru yang diberikan oleh guru. Selain itu, fitur pengelompokan dapat diperbaiki dengan metode yang lebih baik sehingga pengelompokan lebih merata serta dapat dilakukan penambahan jenis permainan agar permainan menjadi lebih beragam.

\section{UCAPAN TERIMA KASIH}

Ucapan terima kasih disampaikan kepada Ibu Nunuk Sri Lisayanti, S.Pd, MM selaku guru dan narasumber di UPT SMP Negeri 6 Gresik, yang sebelumnya bernama SMP Negeri Sidayu 1 Gresik, yang telah bersedia meluangkan waktu serta memberikan ilmu dan dukungan selama penelitian.

\section{REFERENSI}

[1] (2020) "KBBI Daring" [Online], https://kbbi.kemdikbud.go.id/, tanggal akses: 14-Mar-2020.

[2] A. Kurniasari, "Komparasi Hasil Belajar Antara Siswa yang Diberi Metode TGT (Teams Games Tournament) dengan STAD (Student Teams Achievement Division) Kelas X Pokok Bahasan Hidrokarbon,” Skripsi, Universitas Negeri Semarang, Semarang, Indonesia, Jan. 2020.
[3] N.S. Lisayanti, Kaki Si Rita Bikin Aku Hebat, $1^{\text {st }}$ ed., Kudus, Indonesia: Yayasan Sinar Edukasi Mandiri, 2021.

[4] D. Rohendi, H. Sutarno, dan Nopiyanti, "Penerapan Model Pembelajaran Kooperatif Tipe Teams Games Tournament Berbasis Multimedia dalam Meningkatkan Hasil Belajar Siswa Pada Mata Pelajaran Teknologi Informasi dan Komunikasi," J. Pend. Teknol. Inf. dan Komun, Vol. 3, No. 1, hal. 19-22, Jun. 2010.

[5] E. Noviana dan Okimustava, "Penggunaan Metode Pembelajaran Teams Games Tournament (TGT) untuk Meningkatkan Aktivitas dan Prestasi Balajar," J. Riset dan Kajian Pend. Fisika, Vol. 3, No. 1, hal. 16-18, Apr 2016.

[6] L.N.B. Rumayon, J. Prestiliano, dan M.C. Paseleng, "Perancangan Aplikasi Pembelajaran Kooperatif Tipe Team Games Tournament (TGT) Berbasis Web," J. Informatika, Vol. 9, No. 1, hal. 51-63, Apr. 2013.

[7] R.L. Widyawati, S.B. Utomo, dan S. Saputro, "Penerapan Model Pembelajaran Teams Games Tournaments (TGT) Dilengkapi Flash Chemquiz untuk Meningkatkan Minat dan Prestasi Belajar Materi Hidrokarbon pada Siswa Kelas X-8 SMA Negeri 3 Boyolali Tahun Pelajaran 2015/2016," J. Pendidikan Kimia, Vol. 5, No. 4, hal. 7582, 2016.

[8] E. Irwansyah (2017) "Clustering” [Online], https://socs.binus.ac.id/2017/ 03/09/clustering/, tanggal akses: 20-Des-2020.

[9] S.N. Putri, A.H. Brata, dan H. Tolle, "Pengembangan E-Rapor pada Sistem Pembelajaran Siswa Berbasis Web (Studi Kasus: SMAN 1 Bululawang)," J. Pengemb. Teknol. Inf. dan Ilmu Komp., Vol. 1, No. 1 hal. 10765-10770, Feb. 2020

[10] M.W.D. Ridiansyah, F. Pradana, dan N. Santoso, "Pengembangan Sistem Aplikasi Manajemen Distribusi Pupuk Berbasis Web (Studi Kasus: PT Petrokimia Gresik)," J. Pengemb. Teknol. Inf. dan Ilmu Komp., Vol. 3, No. 6, hal. 5357-5365, Jun. 2019.

[11] M.D. Marali, F. Pradana, dan B. Priyambadha, "Pengembangan Sistem Aplikasi Transaksi Bank Sampah Online Berbasis Web (Studi Kasus: Bank Sampah Malang)," J. Pengemb. Teknol. Inf. dan Ilmu Komp., Vol 2, No. 11, hal. 5644-5650, Jul. 2018. 